\title{
A LITERATURA E A VIDA PRÁTICA
}

LITERATURE AND THE PRACTICAL LIFE

\author{
Rogério Lima \\ Doutor em Semiologia pela UFRJ. Docente do Programa de \\ Pós-Graduação em Literatura da UNB. \\ Programa de Pós-Graduação em Literatura \\ Universidade de Brasília (UNB) \\ Brasília - DF - Brasil \\ Endereço: \\ Universidade de Brasília \\ Instituto Central de Ciências - ICC - Centro - Sala 325 \\ Departamento de Teoria Literária e Literaturas \\ Brasília-DF \\ CEP: $70910-900$ \\ E-mail: \\ rlima@unb.br
}

RESUMO

Neste artigo trabalhamos com o conceito de infantilização estética e de necessidade de aproximação da crítica literária da biopolítica. Nosso interesse está centralizado no potencial reflexivo da literatura, como ela proporciona um espaço analítico importante para a teoria e para a estética do texto literário.

PALAVRAS - CHAVE: Estética. Leitura. Literatura. Crítica literária.

ABSTRACT

In this article, we work with the concept of aesthetic infantilization and the need to address the literary critic of biopolitics. Our interest is centered on the potential of reflective literature, as it provides an important space for analyzing the theory and aesthetics of the literary text.

KEYWORDS: Aesthetic. Reading. Literature. Literary criticism.

A apresentação da comunicação intitulada "Crítica política, eurocentrismo e literatura comparada", por Benjamin Abdala J unior, no âmbito do Simpósio Narrativas, relatos e testemunhos no circuito iberoamericano, no 54 ICA - Congresso de Americanistas, em Viena, no ano de 2012, suscitou uma série de questões sobre as formas de abordagem e ensino da literatura na escola e a construção de uma Crítica ligada ao pensamento político. No estudo proposto em sua comunicação, Abdala Junior:

[...] parte da perspectiva de um comparatismo literário de sentido político, focalizando (...) produções literárias dos países de língua portuguesa, tendo em vista destacar a importância da formação de blocos comunitários linguístico-culturais. Se nos situamos num momento de repactualizações políticas em escala planetária, tornam-se particularmente relevantes, para quem se situa no Brasil, articulações com os países de língua portuguesa, e também pelos países de língua espanhola. Dois enlaces básicos, que apontam para uma comunidade iberoafroamericana, sem desconsiderar outras laçadas possíveis, diante do processo de mundialização. (ABDALA JUNIOR, 2012, 5757).

A apresentação provocou uma grande discussão em torno da questão da literatura e seu consumo na escola. A discussão tomou o rumo da reflexão sobre o empobrecimento intelectual e da dificuldade do ensino da literatura nos cursos de letras para os estudantes brasileiros. 
Duas questões surgem em meio a este debate, a primeira é: devemos encarar o fato de vivermos em "tempos empobrecidos" culturalmente, formados, quase que exclusivamente, por consumidores ávidos por colecionar momentos fugazes, criados pelas grandes agências de propaganda e publicidade e alimentados pelo consumo? A outra questão que surge imediatamente a esta é: será que, ao insistirmos sobre a existência de uma literatura, arte ou música "de qualidade", não estaríamos sendo elitistas?

Existe um grande dilema a ser resolvido: ou nos entregamos à orgia do consumo e do consumidor ou resistimos às investidas dos pseudo-educados que não são capazes de atender às regras de civilidade no espaço do café da manhã do hotel barato, de qualquer grande cidade do ocidente. Falta civilidade em alguns jovens e adultos, dos quais esperamos um pouco mais do que rostos amuados, pelo incômodo da convivência matinal forçada, pelo horário restrito do serviço de café da manhã. Referimos-nos aqui a uma classe média que dispõe de recursos para se locomover pelo mundo, impulsionados pelo turismo.

Vivemos num mundo que se pensa prático. Porém, em meio às sucessivas crises econômicas que têm surgido de maneira cíclica na última década, não temos testemunhado muita praticidade. Como tratamos aqui, ainda que de forma muito rápida, de economia, atestar a existência desta falta de praticidade é preocupante.

Quando o discurso da praticidade se volta para o lado da cultura e, em especial, para a literatura ou para o seu ensino e difusão, ou sua permanência, torna-se mais preocupante ainda.

Como tornar prático algo que é provido de uma praticidade abstrata, ou praticidade nenhuma, sem finalidade primeira ou imediata? Como tornar prática a noção de língua que a literatura pode transmitir ao leitor. Como tornar prática a noção de arte que as palavras podem apresentar ou carregar consigo?

Estas noções só podem ser adquiridas com o tempo, com a educação formal e do espírito e algumas imposições da vida vivida. Na economia do tempo, a leitura é muito dispendiosa, ou seja, custa muito caro. O dispêndio de tempo de diversão com uma atividade como a leitura, que exige muita atenção e alheamento, é tratado como uma grande perda de tempo, ainda que reiteradamente se ouça a ladainha de que a leitura seja importante.

No tempo da velocidade, foi a imagem que assumiu o papel de educar esteticamente. Peter Sloterdijk (2000) chama a nossa atenção para o fato do livro ter perdido o seu lugar, ou passar a ocupar um lugar marginal no século XX, diante das inovações tecnológicas que o século conheceu, e que servem ou têm o propósito de difundir informação e cultura: rádio, fonógrafo, cinema, televisão. Os livros perderam o status de cartas, apenas mais longas, dirigidas aos amigos, conforme anota Sloterdijk sobre a definição dada por J ean-Paul Sartre a respeito da natureza e da função do humanismo: "a comunicação propiciadora de amizade realizada à distância por meio da escrita." (SLOTERDJIK, 2000, p. 7).

Em sua crônica "Cinema e educação", a escritora Cecília Meireles ressaltou as qualidades do filme de animação Fantasia (1940), produzido pelos estúdios Disney. Entre as características da produção dos Estúdios Disney apontadas, ela ressaltou, inicialmente, os cuidados que se deve tomar diante dos problemas e das possibilidades de educação estética do espectador, por intermédio de veículos de massa como o cinema.

\footnotetext{
O espetáculo Fantasia, em que Walt Disney reúne uma série de desenhos animados, inspirando-se em famosas peças de música, não corresponde, em certos pontos, ao que muitos espectadores poderiam esperar.
}

O erro foi propalar-se tanto que se tratava de uma espécie de interpretação mágica das músicas escolhidas. Interpretação não deixa de ser. E interpretação é coisa pessoal, que cada um realiza como pode, ou quer, com a máxima liberdade, desde que seja para o seu uso exclusivo. Oferecer ao público uma interpretação que não guarde certa proximidade com o assunto interpretado é desagradável e perigoso. Desagradável, porque as pessoas irreverentes se riem do intérprete. E perigoso, porque as pessoas de boa-fé acreditam na interpretação, e adotam-na.

\section{$[\ldots]$}

Os amadores de música têm sofrido muito com o espetáculo - que é, no entanto, altamente elucidativo sobre o funcionamento da mentalidade americana, partindo de um elemento musical familiar à sensibilidade latina e, especialmente, brasileira. 
Por eles se vêem as diferenças entre estilo de "sonho" de cada povo, e que ausência de profundidade trágica se revela em cada desenho, cujo espírito puramente lúcido de vez em quando tende a deformar-se em visão caricatural.

Fantasia seria mais interessante se outras fossem as músicas escolhidas - já que se desejavam fazer os desenhos sobre música. (MEIRELES, 2003, p. 316 - 7).

Ainda que desde o início de sua crônica Cecília Meireles se revele cautelosa em relação ao filme, reconhece em Fantasia qualidades e uma dessas qualidades é a de o filme permitir a análise de interpretações:

Uma dessas qualidades é, por exemplo, o estudo da peça de Bach. Conseguir prender um salão cheio diante de uma tela onde apenas aparecem e desaparecem filetes, manchas raios, ondas, relâmpagos de cor - eis uma conquista que vem ajudar a todas as outras artes, preparando a sensibilidade do público para a fruição pura - sem contaminações descritivas nem sentimentais. (MEIRELES, 2003, p. 317).

A princípio, tenderíamos a concordar com a análise de Meireles, porém, lendo atentamente a afirmação que autora faz, é possível sustentar que a sensibilidade do público não é preparada "sem contaminações descritivas nem sentimentais" (MEIRELES, 2003, p. 317), esta observação de Cecília dá a Fantasia um caráter despretensioso e apenas preparatório, no que diz respeito a qualquer tipo de manipulação do gosto do público. Porém, ao analisarmos as estratégias do entretenimento, principalmente as que têm como origem os estúdios cinematográficos de Hollywood, dificilmente endossaríamos a afirmação de Meireles.

O crítico cultural Neal Gabler destaca algumas estratégias da indústria do entretenimento no sentido de capturar a sensibilidade do seu público:

Já no século XIX, a estética do entretenimento tinha se tornado maior, mais célebre, mais barulhenta, como se o desejo de uma sobrecarga sensória fosse, assim como o sexo, um impulso biológico em estado bruto, difícil de resistir. As platéias preferiam entretenimentos visuais, como o teatro, a outros mais cerebrais, como os romances. Mas a prova mais convincente do nexo entre entretenimento e sensação só viria bem mais tarde, com a chegada do cinema e da televisão. Esses passatempos tão populares foram também os que mais diretamente atacaram as vísceras e mais ativamente estimularam os sentidos, ainda que o entretenimento jamais fosse desistir de buscar sem descanso novas maneiras de aumentar o valor da aposta sensória. (GABLER, 1999, 24 - 5).

Gabler relata uma das estratégias dos Estúdios Disney para tirar proveito máximo da relação entre esporte e cinema:

A Disney fez um filme popular, intitulado The Migthy Ducks [Nós somos os campeões], sobre um grupo de jovens pobres que acabam formando um time campeão de hóquei. Em seguida comprou a franquia de um time da Liga Nacional de Hóquei, batizou-o com o nome de Migthy Ducks, usou o mesmo emblema usado no filme e chamou sua quadra de The Pond [A Lagoa]. Num golpe brilhante de merchandising cruzado, o filme (e as sequências rodadas depois) vendia o time de hóquei, enquanto o time hóquei vendia os filmes, e ambos vendiam os produtos com o emblema do pato [duck]. (GABLER, 1999, p. 116).

Esta mesma estratégia seria utilizada em outra oportunidade. Ao lançar uma refilmagem do filme Angel in the Outfield [Anjos e piratas], a companhia Disney lançou mão da mesma estratégia e "comprou uma parte do time de beisebol Angels, da Califórnia, e mudou o uniforme dos jogadores, para que ficasse igual ao usado no filme." (GABLER, 1999, p. 116).

Analisando por esse ângulo, é difícil endossar a opinião de Cecília Meireles de que os produtores de Fantasia estivessem munidos apenas da intenção de preparar "a sensibilidade do público para a fruição pura - sem contaminações descritivas nem sentimentais." (MEIRELES, 2003, p. 317).

Mas o propósito de Cecília não é o de aprofundar-se numa discussão sobre o uso do entretenimento e a precariedade do sublime frente ao domínio do divertido. Meireles, após anotar o que considerava como problema, na sua rápida análise sobre Fantasia, volta-se para o que identificou como sendo possibilidades de aplicações educacionais do cinema:

Mas em certos casos, só o desenho animado está em condições de tornar visíveis e compreensíveis coisas que, apenas através dos livros, parecem difíceis ou áridas. 
Principalmente no tempo atual, em que as pessoas entendem com mais clareza vendo do que lendo, por influência do mesmo cinema, que, de tanto apresentar as coisas nos seus menores aspectos, amortece a imaginação - é necessário aproveitar do cinema tudo quanto possa oferecer de vantajoso, para compensar os prejuízos que é capaz de causar.

Os desenhos de Walt Disney para a música de Stravinsky podem desgostar os amadores da música, pela possível diferença de interpretações. Considerando-se, porém, o desenho separadamente, não se pode deixar de apreciar toda a sugestão que nele existe, de tempos impossíveis de recapitular, em sua extensão e com seus panoramas, sem o auxílio dessa técnica, de maravilhoso poder.

Além disso, é o cinema um grande livro que pode ser visto, ao mesmo tempo, por um grande público - e uma boa coleção de filmes científicos, fortes e vivos, como essa pré-história de Walt Disney, equivaleria a uma biblioteca de divulgação científica, uma biblioteca ambulante, indo até às populações rurais, até os iletrados, para os quais um locutor discreto, sem bizantinismos de linguagem nem de voz, serviria de explicador - ampliando a órbita de cultura das classes mais desfavorecidas. (MEIRELES, 2003, 318)

Efetivamente, Cecília Meireles, como grande artista que era, percebeu possibilidades no uso do cinema que eram e viriam a ser amplamente utilizadas no gênero documentário ao longo do século $\mathrm{XX}$ e até mesmo no Brasil.

A imagem, principalmente aquela que é veiculada pela televisão brasileira, tem cuidado de discutir e educar esteticamente o seu consumidor. Um dos seus produtos, a telenovela, tem se dedicado a temas como moda, artes plásticas, música popular e adaptação literária. Isto sem mencionarmos a questão religiosa que tem perpassado, não tão sutilmente, a temática adotada pela teledramaturgia novelística. O catolicismo, o espiritismo e a temática evangélica assumiram papéis preponderantes na telenovela brasileira. O mesmo não aconteceu com a Umbanda ou com o Candomblé. Alguns até poderão dizer que de todo não é bem assim, pois o Candomblé se faz presente nas adaptações das obras literárias de Jorge Amado. Sim, é verdade, porém esta inclusão se faz pelas exigências da obra, não por uma escolha e estratégia mercadologicamente pensada.

Se o filme Fantasia "educa" as sensibilidades para a música, outra criação cinematográfica, em forma de animação, atrai a atenção do espectador para o modo como nos alimentamos: Ratatouille (2007), produção dos Estúdios Disney e da Pixar Feature Films.

O filme de animação Ratatouille conta a história de Rémy, um rato que vive em Paris e que tem como grande sonho se tornar um chefe de cozinha. Rémy se destaca da rataria por ter desenvolvido uma forma muito particular de se alimentar, fazendo harmonizações com os diversos tipos de alimentos que encontra nas cozinhas dos restaurantes parisienses. Desta forma, o personagem Rémy, que se recusa a comer lixo, encontra o prazer estético e gastronômico na alimentação, para além do simples atendimento da necessidade de saciar a sua fome com restos de comida. Do ponto de vista da estética do entretenimento, Ratatouille é perfeito na combinação que faz entre criação de efeitos "estéticos", que pré-digerem a arte para o espectador, fornecendo uma espécie de atalho para o prazer da arte, e o divertido. É importante ressaltar que a gastronomia tornou-se um tema da moda e a profissão de chefe de cozinha, glamourizada, uma das novas metas profissionais de jovens da classe média brasileira.

Como contraponto ao rato Rémy, aberto aos novos sabores que as cozinhas dos restaurantes franceses podem oferecer a um gourmet, temos o crítico gastronômico que constrói a sua fama e o seu "respeito" a partir da demolição da reputação alheia. O crítico gastronômico representado em Ratatouille, Anton Ego é o seu nome, é alguém soturno, mal-humorado e desagradável, capaz de dizer coisas como: "Yes, I'd like your heart roasted on a spit. Heh heh heh heh. Ha ha ha!"1. Coincidência ou não a figura de Ego remete ao aterrorizador vampiro Nosferatu, personagem principal do filme de F. W. Murnau, Nosferatu: a sinfonia do horror (1922). O mal-humorado crítico Egon, por sua vez, aterrorizou, com suas críticas impiedosas, o chefe Gusteau, proprietário do restaurante Gusteau's, terminando por levá-lo à morte.

Ratatouille é pouco condescendente com a figura do intelectual representado no filme pelo crítico e pela crítica. O filme reputa o mal-humor dos dois, do crítico e da crítica, à perda da sensação de prazer que as coisas simples podem produzir, que ficou esquecida na infância, permanecendo apenas num canto "empoeirado" da memória. 
No tempo da velocidade, a Crítica é um luxo que pressupõe a existência de leitores interessados no que ela diz e sobre o que ou a quem ela fala. A compreensão do seu papel é algo difícil para senso comum, pois a ideia de criticar, pelo menos para o homem médio brasileiro, continua ligada à noção de falar mal de algo ou alguém, ou então está ligada à ideia de denúncia.

Estamos perdendo leitores e não nos damos conta do que está acontecendo à nossa volta. O poeta e articulista Pedro Mexia (2012, p. 21) chama a nossa atenção para o fato de os jornais estarem desaparecendo. A chamada "morte dos jornais", segundo Mexia, teria se iniciado com a descontinuação da edição impressa diária do periódico, hoje semanal, Christian Science Monitor, em setembro de 2008.

Para a grande maioria, não fazia grande diferença, aquele jornal não era mundialmente famoso, e a ligação à bizarra "Igreja de Cristo Cientista" não ajudava. Mas na verdade tratava-se de uma publicação respeitadíssima, com uma boa cobertura de política internacional e Pulitzes no currículo.

Fundado em 1908, o jornal sobreviveu cem anos, até passar a existir apenas em edição digital.

Muitas cronologias da "morte dos jornais" apontam o fecho do CSM como o princípio do fim. Segundo incontáveis artigos e estudos, em 2018 não haverá jornais e o desaparecimento do Diário de Boston foi o "momento zero".

A lógica para esta afirmação está calcada no fato de que, quando morre um leitor de jornais, ninguém o substitui. A conclusão a que se chega, após uma avaliação demográfica e das tiragens dos jornais, dão à imprensa apenas uma década de vida, a contar de 2008. A descontinuação do Christian Science Monitor repetiu-se de forma mais drástica com o centenário diário carioca J ornal do Brasil, em setembro de 2010, passando a ser publicado apenas em formato digital. O J ornal do Brasil representou, ao longo da sua existência impressa, uma trincheira de resistência política e cultural no Brasil, principalmente no período do governo militar.

O J B, como era carinhosamente conhecido, criou alguns dos suplementos culturais e literários mais importantes do Brasil: "Suplemento Dominical" e "Ideias", além do famoso Caderno B, referência de jornalismo cultural de alta qualidade na imprensa brasileira. A diagramação elegante do jornal proporcionava grande prazer no momento da leitura. O JB impresso era o jornal em que Carlos Drummond de Andrade publicava a sua crônica, três vezes por semana, às terças, às quintas e aos sábados. Foram 2.300 textos, resultado de uma parceria que teve início em 2 de outubro de 1969, com a publicação da crônica "Leilão no ar" e se estendeu até 29 de setembro de 1984, com a crônica "Ciao".

Nas páginas do JB também podíamos encontrar Millor Fernandes e Zózimo Barroso do Amaral, entre outros importantes articulistas do jornalismo carioca e nacional. Ter uma assinatura do J B era motivo de orgulho e símbolo de status intelectual e de estar em dia com a vanguarda da análise política e cultural do Brasil e do mundo.

Do ponto de vista do leitor que, no seu café da manhã, além do reconfortante aroma do café, ansiava pelo odor, e tudo o mais que ele representava, do seu jornal matinal, em que sujava os dedos de tinta de impressão, antes de partir para a sua jornada de trabalho diária, a ideia do desaparecimento do jornal impresso parece assustadora. Já existe pelo menos uma geração que desconhece a sensação da textura do papel no qual o jornal é impresso, o cheiro da tinta de impressão, o ruído da página sendo folheada ou dobrada, as estratégias para dobrar o jornal no ônibus ou o trem enquanto ele é lido. Não se trata aqui de sermos nostálgicos, mas de percebermos que estamos perdendo sensações que permeavam as nossas vidas, todos os dias, pela manhã. Sem falarmos na perda da possibilidade de reflexão verticalizada que o jornal diário pode proporcionar com seus artigos longos, ensaios e editoriais.

Mexia elenca aqueles que ele chama de indícios de um mundo que chegou ao fim: perda de leitores, diminuição de tiragens e vendas, publicidade escassa, demissão de pessoal, supressão de suplementos, textos cada vez mais curtos, brindes, "uma sucessão de evidências, medidas de emergência, indícios de um mundo que chegou ao fim." (MEXIA, 2012, p. 21).

O articulista põe uma questão interessante para o leitor: 
A idéia de "crise" é superficial: os jornais não vão acabar por causa da deserção dos anunciantes, dos custos de produção, do aparecimento do digital ou da existência de um novo "modelo de negócio"; os jornais vão morrer porque as pessoas não sentem falta deles [...]. (MEXIA, 2012, p. 21).

Ainda, segundo o autor, "não é apenas o "papel do jornal", como suporte, que vai terminar: o que acabou foi o papel dos jornais." (MEXIA, 2012, p. 21).

A posição de "referência" que a imprensa ocupava foi trocada pelo diz - que - disse das chamadas "redes sociais". Vivemos a época do Breaking news e da "agregação de conteúdos" fora de contexto, e sem comentário, "exceto, obviamente aquele que assume a forma de "interatividade" porque desdenhar da interatividade é "elitista" e a cacofonia é que é "democrática” (MEXIA, 2012, p. 21).

Esta discussão faz com que retomemos ao debate provocado por Benjamin Abdala J r. e à questão que levanto de que a superficialidade venha a ser a lógica do nosso tempo e aqueles que teimam em se baterem por mais conteúdo e profundidade não acompanharam a evolução dos tempos chamados pós-modernos.

Mexia finaliza o seu texto destacando o fato de Steve Jobs ter se tornado o ícone da segunda década dos anos 2000. A década da morte dos jornais canonizou Jobs, o homem. O homem que sem titubear minimizou a discussão sobre a "crise" e "suportes", garantindo que "people don't read anymore"2; esta frase que, numa leitura rápida, parece soar como um lamento, mas, na realidade, é lida pelo articulista como uma espécie de celebração.

O poema Acontecimento, de Vinícius de Moraes, deixado inédito pelo poeta, traduz bem o espírito do nosso tempo:

Haverá na face de todos um profundo assombro E na face de alguns risos sutis cheios de reserva Muitos se reunirão em lugares desertos

E falarão em voz baixa em novos possíveis milagres Como se o milagre tivesse realmente se realizado Muitos sentirão alegria

Porque deles é o primeiro milagre

E darão o óbolo do fariseu com ares humildes Muitos não compreenderão

Porque suas inteligências vão somente até os processos

E já existem nos processos tanta dificuldades...

Alguns verão e julgarão com a alma

Outros verão e julgarão com a alma que eles não têm

Ouvirão apenas dizer...

Será belo e ridículo

Haverá quem mude como os ventos

E haverá quem permaneça na pureza dos rochedos No meio de todos eu ouvirei calado e atento, comovido e risonho Escutando verdades e mentiras Mas não dizendo nada

Só a alegria de alguns compreenderem bastará Porque tudo aconteceu para que eles compreendessem Que as águas mais turvas contêm às vezes as pérolas mais belas (MORAES, 1993, 236).

O poema de Vinícius escrito próximo de sua morte mostra como o poeta percebia o seu tempo. A marca cética e sarcástica que Vinícius imprime ao poema continua atual no tempo presente, no século XXI. Acontecimento registra aquela que Russel Kirk classificou como “[...] uma era de propaganda secular, de uma comodidade inimaginável aos modismos e fraquezas, e de manipulação das massas." (KIRK, 2011, p. 244).

É certo que o mundo prático, gerido pela economia, "por hora em crise", não fala em possibilitar o surgimento de artistas e novas obras de arte, não fala em educar o espírito humano e formar consciências estéticas. O que mais ouvimos é a expressão "formação de mão de obra". No Brasil, o capitalismo criou uma situação paradoxal no que diz respeito à formação de mão de obra: nos últimos cinquenta anos, as classes menos favorecidas foram tão espoliadas em termos de formação educacional que hoje o país sofre um apagão de mão de obra, ou seja, uma falta quase que absoluta de trabalhadores qualificados para atuarem em diversos seguimentos do mercado de trabalho. 
Por outro lado, o país conta com uma reserva de mão de obra praticamente inútil. Pois, sem formação adequada, as pessoas que, hoje, estão nesta situação, se encontram incapacitadas para assumir postos de trabalho que exigem formação educacional mais complexa e adequada para que venham a ser ocupados. Várias atividades, que há algum tempo eram consideradas simples, adquiriram uma complexidade tecnológica tamanha, que passaram a exigir formação específica para a execução de todos os processos envolvidos nos seus exercícios. Acreditamos que muitos não compreenderão nem os processos de que trata o poema de Vinícius: “Muitos não compreenderão/Porque suas inteligências vão somente até os processos/E já existem nos processos tanta dificuldades..." (MORAES, 1993, p. 236).

Assim como o poema de Vinícius de Moraes, a conversa citada por Russel Kirk, havida entre I. A. Richards e um dirigente do Lloyd's Banks, o senhor W., sobre T. S. Eliot (Thomas Stearns Eliot), então empregado do banco, é também bastante esclarecedora sobre o nosso tempo e sobre a forma como o mundo prático se comporta em relação à arte e sobre o que pensa de seus artistas. O senhor W. perguntou a Richard se Eliot era mesmo um bom poeta, ao que Richard responde afirmativamente. À resposta afirmativa de Richard o senhor W. declarou:

\begin{abstract}
Sabes, estou mesmo muito feliz de ouvir-te dizer isso. Muitos de meus colegas absolutamente não concordariam. Pensam que um escriturário não tem nada que ser poeta... mas creio que qualquer coisa que um homem faça, qualquer coisa que seja seu passatempo, tanto melhor se realmente tem pendor e o faz bem... na verdade, caso ele continue a se sair como está, não vejo por que - no devido tempo, é claro, no devido tempo - ele não possa se tornar gerente de uma filial. (KIRK, 2011, p. 238)
\end{abstract}

Certamente, seria inconveniente exigir do senhor W., dirigente do Lloyd's Banks, importante agente financeiro inglês no século XX, qualquer conhecimento sobre arte, muito menos de literatura moderna contemporânea, para que pudesse reconhecer e dar valor a um dos mais importantes poetas modernista de língua inglesa. Não desejamos afirmar aqui que o mundo da economia venha a ser desprovido de sensibilidade artística. O economista J ohn Maynard Keynes, sabendo do valor de T. S. Eliot, hipotecou apoio à indicação do seu nome para o cargo de editor de um dos mais importantes periódicos ingleses dos anos 1920, o The Nation and Athenaeum, para livrá-lo do emprego de escriturário no Lloyd's, que consumia tempo precioso para Eliot se dedicar à poesia.

Na realidade, o senhor $W$. é um dos representantes do mundo de homens ocos dos quais fala Eliot no seu poema "Homens ocos".

A penny for the Old Guy ${ }^{3}$

Nós somos os homens ocos Os homens empalhados Uns nos outros amparados O elmo cheio de nada. Ai de nós Nossas vozes dessecadas

Quando juntos sussurramos, São quietas e inexpressas Como o vento na relva seca Ou pés de ratos sobre cacos Em nossa adega evaporada Fôrma sem forma, sombra sem cor Força paralisada, gesto sem vigor;

Aqueles que atravessaram De olhos retos, para o outro reino da morte Nos recordam - se o fazem - não como violentas

Almas danadas, mas apenas Como os homens ocos Os homens empalhados.

II

Os olhos que temo encontrar em sonhos No reino de sonho da morte Estes não aparecem:

Lá, os olhos são como a lâmina Do sol nos ossos de uma coluna

Lá, uma árvore brande os ramos

E as vozes estão no frêmito

Do vento que está cantando Mais distantes e solenes

Que uma estrela agonizante.

Que eu demais não me aproxime

Do reino de sonho da morte 
Que eu possa trajar ainda Esses tácitos disfarces
Pele de rato, plumas de corvo, estacas cruzadas E comportar-me num campo Como o vento se comporta Nem mais um passo

- Não este encontro derradeiro No reino crepuscular

Esta é a terra morta

Esta é a terra do cacto

Aqui as imagens de pedra

Estão eretas, aqui recebem elas

A súplica da mão de um morto Sob o lampejo de uma estrela agonizante.

E nisto consiste

O outro reino da morte:

Despertando sozinhos

À hora em que estamos

Trêmulos de ternura

Os lábios que beijariam

Rezam as pedras quebradas.

Os olhos não estão aqui Aqui os olhos não brilham Neste vale de estrelas tíbias Neste vale desvalido Esta mandíbula em ruínas de nossos reinos perdidos

Neste último sítio de encontros J untos tateamos Todos à fala esquivos Reunidos na praia do túrgido rio

Sem nada ver, a não ser Que os olhos reapareçam

Como a estrela perpétua Rosa multifoliada

Do reino em sombras da morte A única esperança De homens vazios.

Aqui rondamos a figueira-brava

Figueira-brava figueira-brava Aqui rondamos a figueira-brava Às cinco em ponto da madrugada

Entre a idéia E a realidade Entre o movimento E a ação

Tomba a Sombra

Porque Teu é o Reino

Entre a concepção E a criação

Entre a emoção E a reação

Tomba a Sombra

A vida é muito longa

Entre o desejo

E o espasmo

Entre a potência

E a existência

Entre a essência

E a descendência

Tomba a Sombra

Porque Teu é o Reino

Porque Teu é

A vida é

Porque Teu é o

Assim expira o mundo

Assim expira o mundo

Assim expira o mundo

Não com uma explosão, mas com um suspiro.

Alguns poderão dizer que o exemplo de T.S Eliot é conservador, pois Eliot era considerado um conservador, por, assumidamente, pretender, em sua revista Criterion (1922), preservar a tradição literária: 
A Criterion pretende analisar os primeiros princípios ao criticar, valorar o novo e reavaliar as antigas obras literárias, conforme princípios, e esclarecê-los em escritos criativos. Quer determinar do valor da literatura para outras atividades humanas e tem o propósito de afirmar a ordem e a disciplina no gosto literário. (KIRK, 2011, p. 242).

No nosso tempo, esta declarada intenção de querer "determinar do valor da literatura para outras atividades humanas" e ter "o propósito de afirmar a ordem e a disciplina no gosto literário" certamente renderia muitas críticas.

Perguntamos: não seremos, todos nós que defendemos a "tradição", conservadores pelo fato de não assimilarmos e não nos entregarmos à sedução da estética infantilizada das campanhas comerciais de televisão, nos mantendo fiéis a modelos estéticos e valores culturais considerados "ultrapassados" ou maçantes? Estes produtos culturais só adquirem valor para o senso comum quando servem como prova de realização do turismo de massa "pseudo-cultural", ou seja, o bem cultural só adquire valor quando pode ser exibido como troféu digital, fotografia de afirmação turística, que nem sempre está carregada de emoção positiva, ou quando serve de trilha sonora para embalar a campanha publicitária de qualquer produto moderninho ou a "consciência socioecológica" de alguma multinacional com sede no Brasil.

Um grande número de visitantes do Museu do Louvre, após enfrentar filas, frio, chuva, revistas, corre ávido, atravessando displicentemente galerias de história cultural das artes plásticas ocidental, para ver a Mona Lisa. Uma vez que consegue chegar até o quadro, de lá retorna como se tivesse tomado um banho de água-fria, decepcionados com o tamanho da tela 77 x $55 \mathrm{~cm}$ e com as condições impostas para a fruição da obra, mas esta última questão é a que menos importa, pois o impacto das dimensões da obra é o que mais choca a imaginação do espectador. Some-se a isso o fato de alguns espectadores se munirem de um roteiro traçado a partir da leitura de O código da Vinci, de Dan Brown, para visitar a obra; ignorando o próprio museu como espaço cultural ligado à formação do gosto estético. É possível que este seja o nosso Zeitgeist (Espírito da época).

É possível que esse espírito da época esteja sendo captado pelos grupos de Axé music; pelas duplas sertanejas, com o seu pseudo-erótico romantismo de duplo sentido; pelas duplas de criação, nas agências de propaganda e publicidade, com os seus comerciais infantilmente coloridos e também embalados em músicas infantis, tradicionais, como as campanhas comerciais de algumas montadoras automobilísticas para os seus novos modelos de automóveis lançados no país; ou com personagens de propaganda de cerveja, sonhando em se tornarem invisíveis para entrarem nos banheiros femininos, sem serem vistos. Esta é uma das velhas etapas da imaginação erótica da adolescência masculina.

Este processo de infantilização é tão intenso que algumas companhias de aviação substituíram as demonstrações de medidas de segurança em seus aviões por filmes de animação com personagens de madeira, ou parecidos com os personagens das animações de comerciais de amaciante de roupas. Talvez este seja o reconhecimento comercial, para além do entretenimento, do potencial do desenho animado, expressão antiga, hoje dizemos filme de animação, que Cecília Meireles considerava conter um alto potencial educativo, um mal com pontos positivos a serem considerados.

Porém é possível que a percepção do nosso Zeitgeist, hoje, seja um dos atributos dos profissionais de marketing. O escritor Colin Wilson descreve a desconfiança que tinha desta expressão e do seu significado:

[...] Uma vez , tive uma intensa suspeita e desconfiança em relação à palavra Zeitgeist, porque não conseguia compreender como uma época podia ter um espírito. No entanto, Scott Fitzgerald escreveu sobre o próprio período, com o que ganhou muito mais dinheiro do que ele teria podido sonhar, só por ter dito ao público que sentia como ele. Parece estar a acontecer o mesmo a um número de escritores jovens dos nossos dias - e eu incluo-me neles - , para os quais talvez exista, afinal, isso que se convencionou chamar o "espírito da época". Foi assim que cheguei à aceitação de que "a época" poderia sentir possivelmente as mesmas necessidades que eu sinto, e abandonou-me o temor de que talvez estivesse somente vendo um reflexo distorcido do meu próprio rosto. (WILSON, 1963, p. 37 - 38).

Outro ator do "espírito da nossa época" é o medo. O medo desempenha papel preponderante na sociedade contemporânea tendo sido incorporado, por exemplo, como tema de análise culturalsócio-filosófica por Zigmunt Baumann e da arte cinematográfica, por Win Wenders, em O fim da violência (1997); e pelo Duo Thievery Corporation, formado por Eric Hilton e Rob Garza, em seu 
sexto álbum de estúdio, Culture of fear (2012). O medo no nosso tempo traduz-se em medo do desemprego; do atentado terrorista; da perda de poder aquisitivo; do aquecimento global; da crise monetária, que teima em retornar sempre; da violência urbana; etc. Jurandir Freire Costa vê o medo como um gerador de armadilhas do pânico, no qual "a lógica da brutalidade nivela por baixo os sentimentos". (COSTA, 1993, p. 85).

É possível ler o poema Acontecimento como manifestação do "espírito da época" percebido por Vinícius de Moraes e anotado antes por T. S. Eliot em Os homens ocos. Este Zeitgeist perdurou ao logo do século XX e adentrou o XXI com poder máximo. A sua principal característica seria o decréscimo do valor da razão e uma supervalorização das sensações e do entretenimento, trazendo consigo uma consigna: devemos nos entregar a tudo que seja fun (divertido).

No tempo do efeito e da diversão, a crítica não teria mais lugar, pois o perdeu para o entretenimento, que assumiu o seu espaço tradicional e tornou-se crítico da crítica. Assim como o filme Ratatouille poderia ser interpretado como uma espécie de metáfora sobre como os humanos se comportam como uma colônia de ratos, ao se alimentarem de um tipo de comida que mais envenena do que alimenta - e que não teria lugar em qualquer restaurante que preze este nome -, ele pode ser interpretado também como um posicionamento antirracional, diluidor, que direciona o espectador do entretenimento para o efeito que pré-digere a arte e possibilita que ele alcance um atalho para o prazer da arte.

Apesar de ver o cinema como um possível e poderoso aliado do professor, Cecília Meireles percebia alguns problemas nos filmes e um deles residia na forma como os objetos filmáveis reconstituídos, os temas históricos, por exemplo, são interpretados e apresentados ao público. Para ela, era imperativo aproveitar do cinema tudo quanto pudesse oferecer de vantajoso, a fim de compensar os prejuízos que pudesse vir a causar (MEIRELES, 2003, p. 318). Já no ano de 1940, a autora registrava em sua crônica a consolidação da cultura visual em detrimento da leitura. Meireles anotou que as pessoas, por influência do cinema, entendiam melhor os fatos vendo-os do que lendo sobre eles. Pois o cinema, de tanto apresentar os acontecimentos em seus menores aspectos, amortecia a imaginação do espectador (MEIRELES, 2003, p. 318).

Finalizando, diríamos que existe uma estética particular para cada métier que remete aquele que por ele transita para um espaço particular onde hoje estão intimamente relacionados elementos estéticos importantes: efeito, beleza, prazer e o mais essencial de todos: diversão.

\section{REFERÊNCIAS}

ABDALA JUNIOR, Benjamin. "Crítica política, eurocentrismo e literatura comparada" in 54 ICA - Congresso internacional de americanistas - Caderno de Resumos. Viena: Universität Wien/Museum Für Völker Kunder, 2012, resumo 5757.

ANDRADE, Carlos Drummond. "Leilão no ar", Jornal do Brasil, Rio de Janeiro, 02 de outubro de 1969. URL: http://www.jb.com.br/especial-drummond/noticias/ 2012/07/ 01/a-1a-cronica-no-jornal-do-brasilleilao-do-ar-em-outubro-de-1969/, última consulta 10/09/2012.

. "Ciao", Jornal do Brasil, Rio de Janeiro, 29 de setembro de 1984. URL: http://www.jblog.com. $\mathrm{br} /$ hojenahistoria. php?itemid=28530, última consulta 10/09/2012.

COSTA, J urandir Freire. "O medo social” in Veja 25 anos: reflexões para o futuro. São Paulo: Abril, 1993, p. $83-89$.

GABLER, Neal. Vida o filme: como o entretenimento conquistou a realidade. Tradução Beth Vieira. São Paulo: Companhia das Letras, 1999.

ELIOT, T. S. POESIA. Tradução, introdução e notas I van J unqueira. Rio de Janeiro: Nova Fronteira, 1981. (Coleção Poiesis).

KIRK, Russel. A era de T. S. Eliot: a imaginação moral do século XX. Tradução Márcia Xavier de Brito. São Paulo: É Realizações Editora, 2011. (Coleção Crítica, história e teoria da literatura). 
MARKOFF, John. The passion of Steve J obs. New York Times Technology. Disponível em: http://bits. blogs. nytimes.com/2008/01/15/the- passion- of-steve-jobs/ ?ex=13582260 00\&en=dc35254b0fcd5490\&ei=509 $0 \&$ partner $=$ rssuserland\&emc=rss. Última consulta em 31/08/2012.

MEXIA. Pedro. "Daqui a seis anos" in Revista Ler: livros \& leitores. Julho/Agosto, 2012, Número 115. Segunda série. Lisboa. p. 21.

MORAES, Vinícius. "Acontecimento" in Veja 25 anos: reflexões para o futuro. São Paulo: Abril, 1993, p. $236-237$.

SLOTERDJIK, Peter. Regras para o parque humano: uma resposta à carta de Heidegger sobre o humanismo. Tradução de José Oscar de Almeida Marques. São Paulo: Estação Liberdade, 2000, p. 7.

WILSON, Colin. "Para além do outsider" in Depoimentos dos "Angry men". Tradução Artur Portela Filho. Lisboa: Editorial Presença, 1963. Perspectivas.

FILMOGRAFIA

Fantasia. Estúdios Walt Disney. EUA, 1940.

Nosferatu, eine Symphonie des Grauens . Direção: F. W. Murnau, Alemanha, 1922.

Ratatouille. Direção: Brad Bird/Jan Pinkava. Disney/Pixar Feature Films. EUA, 2007.

$1 \mathrm{Sim}$, eu gostaria do seu coração assado num espeto. Heh heh heh heh. Ha ha ha!

2 "as pessoas não leem mais".

3 Um pêni para o Velho Guy.

Artigo recebido em 01/08/2012 Aprovado em 11/09/2012 